\title{
LOSS OF HEIGHT PRESSURE IN A LAYER OF GRANULAR MATERIALS
}

\author{
Adrian VASILIU \\ "Dunarea de Jos" University of Galati, Romania \\ e-mail: avasiliu@ugal.ro
}

\begin{abstract}
During the air blown in the furnace, from the vents to the loading mouth, the gases lost from the initial pressure depend on several factors, such as the care and the granulation mixed with ores and coke from the layers of care. For the knowledge of a gas circulation through granular layers, pressure losses were studied in layers formed from pieces of materials of different shapes and sizes, using a specially constructed laboratory installation.
\end{abstract}

KEYWORDS: blast furnace, gas circulation, pressure loss, ore, coke

\section{Introduction}

The technology of producing iron ore from blast furnaces consisted of the passage of ore and solid fuel through an upward flow of hot gases with reducing properties. The load consisting of successive portions of ore and coke is introduced at the upper part of the furnace. Getting to the lower parts, the load takes up the heat of the ascending gases, until the temperature of the material reaches softening-melting temperatures. Also, in this range of increase in temperature of solids by heat exchange, some of the reducing gases participate in the indirect reduction of metal oxides, removing oxygen from oxides resulting in weight loss of the solid phase. It is important that the heat-reducing gases travel through the layers of material towards the upper areas of the load, yielding heat from the materials in the column and at the same time ensuring the reduction of the metal oxides [2, 3].

Gas flows at the mouth of the furnace and within the radius, in the respective section, the temperature and the analysis of the gas may have different values, the character of the operation being peripheral, central, combined or non-uniform.

The reducing gases obtained in the area of the windmills have a temperature between $1800-2000{ }^{\circ} \mathrm{C}$, mainly in the component $\mathrm{CO}, \mathrm{H}_{2}$ and $\mathrm{N}_{2}$, the reducing components represent about $36-54 \%$ of the total quantity, the percentage depending on the percentage of $\mathrm{O}_{2}$ of the blown air and the amount of additional fuel introduced into the mouths of the wind. Ideally, the gas flow through the furnace should be evenly distributed, ensuring the same heat transfer per unit area, as well as participating in reductions, it would mean that the lowering of the materials in such a situation would be very uniform. Basically, the load of the furnace has many discontinuities both in terms of the uniformity of the granulation and of the relative distribution on the loading surface [2].

\section{Objectives}

For a more in-depth knowledge of gas flow through the furnace, the pressure loss in layers formed from pieces of material of unequal shapes and sizes, on specially constructed installations was studied.

The practical phase of the work consists in the execution of a laboratory installation to determine the permeability through granular layers.

The obtained results can lead to the completion of the database, so the technical and economic indicators obtained are elements of the automatic program management process in the blast furnace.

\section{Theoretical considerations}

During wind gusts - the loading mouth, the reducing gases lose their initial pressure, the degree of loss depending on the granulation of the mixture of ores and coke from the layers they pass through [6].

Losses due to friction, between the walls of the enclosure and the fluid stream, find their physical explanation through the process of dissipation of hydraulic energy, process conditioned by the viscosity of the fluid and the character of the flow. The calculation relation is as follows [4]: 


$$
p_{f}=\mu \cdot \frac{L}{d_{m}} \cdot \frac{w_{0}^{2}}{2} \cdot \rho_{0 g}\left(1+\alpha \cdot t_{g}\right)\left[N / m^{2}\right]
$$

where:

$p_{f}$ - is the pressure lost by the friction between the gases and the granular materials in the load, $\left[\mathrm{N} / \mathrm{m}^{2}\right]$;

$\mu$ - coefficient of friction material and gas, (air));

$L$ - the length of the gas route [m];

$d_{m}$ - inner diameter inside $[\mathrm{m}]$;

$\rho_{0 g}-$ gas/air density, normal conditions $\left[\mathrm{kg} / \mathrm{m}^{3}\right]$;

$w_{0}^{2}$ - air velocity, normal conditions $[\mathrm{m} / \mathrm{s}]$;

$t_{g}$ - hot air temperature $\left[{ }^{\circ} \mathrm{C}\right]$;

$\alpha$ - the temperature coefficient $(\alpha=1 / 273)$.

Losses due to local resistances occur due to section changes, bends, seals that lead to the corresponding change in fluid velocity. The resistances that cause these changes are called local resistances and are calculated with relations [4]:

$$
p_{r l}=\xi \cdot \frac{w_{0}^{2}}{2} \cdot \rho_{0 g}\left(1+\alpha \cdot t_{g}\right)\left[N / m^{2}\right]
$$

where:

$\xi$ - is the coefficient of local resistance.

Geometric pressure losses are calculated with the relation [4]:

$p_{g}= \pm H \cdot g\left(\frac{\rho_{0 a}}{1+\alpha \cdot t_{a}}-\frac{\rho_{0 g}}{1+\alpha \cdot t_{g}}\right)\left[N / m^{2}\right]$

where:

$H$ - is the height of the column (layer) of material [m];

$g$ - gravitational acceleration $(\mathrm{g}=9,81)\left[\mathrm{m} / \mathrm{s}^{2}\right]$.

Dynamic pressure losses, due to the change in speed value, occur due to section changes on the gas path. In this case, the Borg relation is used for calculation [4]:

$$
p_{d}=\frac{w_{0 e}^{2}-w_{0 i}^{2}}{2} \cdot \rho_{0 g}\left(1+\alpha \cdot t_{g}\right)\left[N / m^{2}\right]
$$

where:

$$
\begin{aligned}
& w_{0 e}^{2}, w_{0 i}^{2} \text {-the speed of gas at the inlet and outlet } \\
& {[\mathrm{m} / \mathrm{s}] .}
\end{aligned}
$$

Pressure losses through layers, consisting of spherical granules when passing gases, can be determined by the relation $[5,7]$ :

$$
\begin{gathered}
\Delta p=\frac{1,53}{\varphi \cdot 4,2}\left(\frac{30}{R e}+\frac{3}{R e^{0,7}}+0,3\right) \frac{H}{d_{m}} \cdot \frac{\rho \cdot w^{2}}{2}\left[N / m^{2}\right] \\
d_{m}=\frac{100}{x_{1} / d_{1}+x_{2} / d_{2}+\cdots+x_{n} / d_{n}}[\mathrm{~m}]
\end{gathered}
$$

where:

$R_{e}$ is Reynolds' criterion $\left(R_{e}=w \cdot d_{e} / v\right)$;

$d_{m}$ - the average diameter of material in the layer;

$x_{1 . . n}$ - the content of the fraction $\mathrm{d}$ in the layer;

$\mathrm{d}_{1 \ldots \mathrm{n}}$ - the average diameter of the granules in a fraction.

\section{Laboratory measurements}

The assessment of the influence of gas pressure on the pressure losses in the layer can be determined. Between the loss of pressure in a layer of materials and the coefficient of resistance (local) of the layer, there is a significant dependence. Based on these relationships and experiments, the variation curves were established for the pressure losses in the layers. Table 1.

The installation for the determination of distributed hydraulic losses is composed of a constant level reservoir that supplies a pipe with the diameter $\mathrm{d}$ $=300 \mathrm{~mm}$, which has at the ends of a straight portion of measurement, with the length $\mathrm{L}=1000 \mathrm{~mm}$, sockets for measuring the pressures with instruments with liquid, as in Figure 1 - A.

The installation consists of a steel tube with pressure sockets at $100 \mathrm{~mm}$ between them, which are connected to U-shaped pressure gauges with water for measuring pressure and a float flow meter, which measures the air flow at the inlet, in the installation (Figure 1-B). The measurements are repeated 5 times, followed by an arithmetic mean of the results.

The results obtained for various materials are shown in Table 1, and the representation is in Graph 1. 

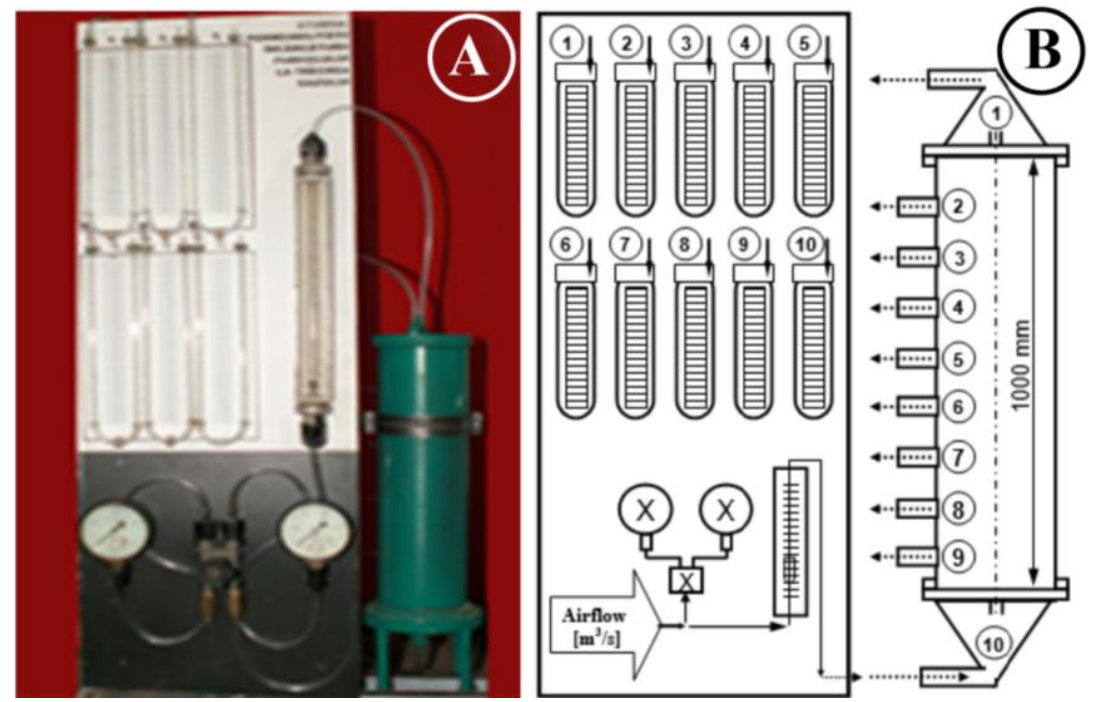

Fig. 1. Installation to determine pressure loss in granular layers

Table 1. Pressure loss in granular layers

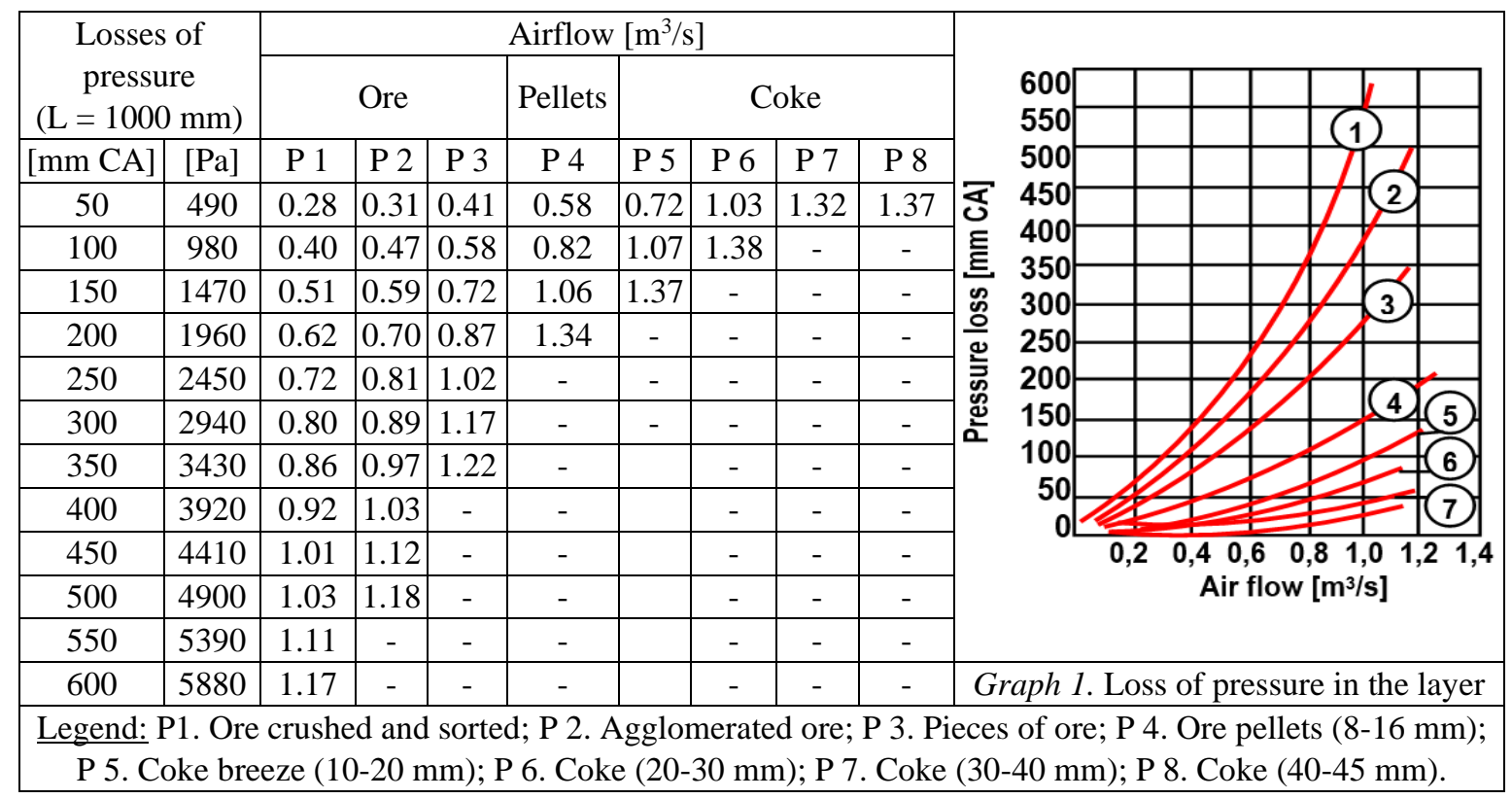

\section{Conclusions}

In order to know the circulation of gases through the furnace, the loss of pressure in layers formed from materials of unequal shapes and sizes, on specially constructed installations was studied.

Variation curves were established for pressure losses in layers of different materials and granulation.

The volume of the voids in the raw material layer depends on the shape and the particle size range of the parts from which the respective layer is formed.

The volume of the gaps between the pieces of materials, as well as the dimensions of this layer derive from the layer and the hydraulic resistance of the gas flow step.

Calculating the pressure loss through the layer, as can be seen from the relations (1), (2), (3), one of the most important factors is the equivalent diameter of the granules from which the layer is formed.

\section{References}

[1]. ***, ArcelorMittal Galați Documentation.

[2]. Buzea O., Furnace, Part II, Sidex - Galați.

[3]. Adrian Vasiliu, Elaboration of the Source in Furnace, electronic format course, UGAL Galati, 2012.

[4]. Adrian Vasiliu, Aggregates and thermal installations, electronic format course, UGAL Galaţi, 2012. 
THE ANNALS OF "DUNAREA DE JOS" UNIVERSITY OF GALATI

FASCICLE IX. METALLURGY AND MATERIALS SCIENCE

No. 1 - 2019, ISSN 2668-4748; e-ISSN 2668-4756

Article DOI: https://doi.org/10.35219/mms.2019.1.10

[5]. Teoreanu I., Becherescu D., Thermo-technological installations, Technical Publishing House, Bucharest, 1999.

[6]. Murguleț N., Nicolae A., Aggregates and industrial thermal

[7]. Nicolae A., Predescu C., Theoretical bases of the thermoinstallations, Bucharest Lithography IPB, 1998. technological aggregates in the metal materials industry, Ed. Printech, București, 2001 